\title{
Oxygen Activation and Reaction on Pd-Au Bimetallic Surfaces
}

\author{
Wen-Yueh Yu, Liang Zhang, Gregory M. Mullen, Graeme Henkelman, and C. Buddie Mullins* \\ McKetta Department of Chemical Engineering and Department of Chemistry, Center for Nano and Molecular Science and \\ Technology, Texas Materials Institute, Center for Electrochemistry, and Institute for Computational Engineering and Sciences, \\ University of Texas at Austin, Austin, Texas 78712-0231, United States
}

\section{Supporting Information}

\begin{abstract}
Pd}-\mathrm{Au}$ bimetallic catalysts have shown promising performance for a number of oxidative reactions. The present study utilizes reactive molecular beam scattering (RMBS), reflection-absorption infrared spectroscopy (RAIRS), temperatureprogrammed desorption (TPD), and density functional theory (DFT) techniques in an attempt to enhance the fundamental understanding of oxygen activation and reaction with $\mathrm{CO}$ on $\mathrm{Pd}-\mathrm{Au}$ surfaces. Our results reveal that the presence of contiguous $\mathrm{Pd}$ sites is crucial for adsorption of oxygen molecules on $\mathrm{Pd} / \mathrm{Au}(111)$ surfaces at $77 \mathrm{~K}$. Upon heating, oxygen admolecules desorbed molecularly without detectable dissociation in $\mathrm{O}_{2}$ TPD measurements. CO-RMBS experiments indicate that at lower temperatures (77$150 \mathrm{~K}$ ) oxygen admolecules were readily displaced by $\mathrm{CO}$ due to competitive adsorption. Oxygen admolecules can be thermally activated at higher temperatures (180-250 K) to react with $\mathrm{CO}$ to form $\mathrm{CO}_{2}$. DFT calculations show that the $\mathrm{Pd}-\mathrm{Au}$ surface containing larger $\mathrm{Pd}$ ensembles favors dissociative $\mathrm{CO}$ oxidation, whereas associative $\mathrm{CO}$ oxidation and $\mathrm{O}_{2}$ desorption are the two main competing processes for the $\mathrm{Pd}-\mathrm{Au}$ surface containing small $\mathrm{Pd}$ ensembles. An associative $\mathrm{CO}$ oxidation pathway was not experimentally observed, which is likely due to facile $\mathrm{CO}$-induced $\mathrm{O}_{2}$ desorption. These results provide mechanistic insights into the interaction of oxygen with $\mathrm{Pd}-\mathrm{Au}$ surfaces, which may prove informative for the rational design of $\mathrm{Pd}-\mathrm{Au}$ catalysts for associated reactions involving $\mathrm{O}_{2}$ as a reactant.
\end{abstract}

\section{INTRODUCTION}

The study of bimetallic catalysts is important in the field of heterogeneous catalysis as bimetallics often exhibit physicochemical properties that are distinctly different from those of the parent metals. These properties provide the potential to design catalysts with enhanced activity, selectivity, and stability. ${ }^{1,2}$ As one of the most extensively studied bimetallic systems, $\mathrm{Pd}-\mathrm{Au}$ catalysts have displayed promising performance in a number of oxidative chemical reactions including $\mathrm{CO}$ oxidation, ${ }^{3,4}$ acetoxylation of ethylene to vinyl acetate, 5,6 selective oxidation of alcohol to aldehyde, ${ }^{7-9}$ and the direct synthesis of hydrogen peroxide from hydrogen and oxygen. ${ }^{10,11}$ A molecular-level understanding of how oxygen molecules interact with $\mathrm{Pd}-\mathrm{Au}$ surfaces (e.g., adsorption, dissociation, and desorption) would be informative for the optimization of Pd$\mathrm{Au}$ catalysts employed for these reactions and other reactions involving oxygen. In model catalyst studies, reactions are normally investigated on well-defined single-crystal surfaces under ultrahigh vacuum (UHV) conditions, which enable the correlation of catalytic properties to surface structures at the molecular level. ${ }^{1,2,12-16}$

Interactions of oxygen with the $\operatorname{Pd}(111)$ single-crystal surface have been studied extensively. ${ }^{17-23}$ It was reported that oxygen molecularly chemisorbs on the $\mathrm{Pd}(111)$ surface at the temperature of $80 \mathrm{~K}^{19}$ High-resolution electron energy loss spectroscopy (HREELS) ${ }^{19,21}$ showed that chemisorbed oxygen molecules exist in three molecular states that exhibit different vibrational frequencies of $\mathrm{O}-\mathrm{O}$ stretching due to varying degrees of electron transfer from the surface into the oxygen molecule. At low coverages (dosed by small exposure of molecular oxygen), adsorbed oxygen molecules dissociate into oxygen adatoms at $\sim 180-200 \mathrm{~K},{ }^{19-21}$ which recombine and desorb from the $\operatorname{Pd}(111)$ surface at temperatures higher than $600 \mathrm{~K}$ in temperature-programmed desorption (TPD) measurements. ${ }^{18,20}$ The direct desorption of oxygen admolecules (without dissociation into oxygen adatoms) was observed when molecular oxygen was dosed on the $\operatorname{Pd}(111)$ surface at high coverages. ${ }^{18,20}$ Three molecular desorption features with peak temperatures of $\sim 125,150$, and $200 \mathrm{~K}$ were observed, ${ }^{20}$ which are consistent with the three molecular states characterized in HREELS spectra. ${ }^{19,21}$ In contrast to the ease of activation on Pd single-crystal surfaces, it is well-accepted that oxygen molecules do not readily activate (or dissociate) on clean $\mathrm{Au}$ single-crystal surfaces. ${ }^{15,24}$

Recently the interaction of oxygen with $\mathrm{Pd}-\mathrm{Au}$ bimetallic model surfaces has been studied both experimentally ${ }^{25-27}$ and theoretically. $^{28-39}$ For example, Tysoe and co-workers ${ }^{25}$ have investigated the interaction of oxygen with $\mathrm{Au} / \mathrm{Pd}(100)$ surfaces with various surface compositions using $\mathrm{O}_{2}$-TPD. Following oxygen exposure at $80 \mathrm{~K}$, direct desorption of oxygen admolecules was observed at 114 and $179 \mathrm{~K}$, and recombinative desorption of oxygen adatoms was detected at $\sim 750 \mathrm{~K}$ during

Received: March 27, 2015

Revised: April 28, 2015

Published: April 29, 2015 
heating. ${ }^{25}$ The coverage of oxygen adatoms was reported to decrease as the gold coverage was increased. ${ }^{25}$ The reaction with $\mathrm{CO}$ to form $\mathrm{CO}_{2}$ is commonly used to probe the reactivity of surface oxygen on $\mathrm{Pd}-\mathrm{Au}$ model surfaces. ${ }^{25-28,32,33,35,37-39}$ By combining reaction kinetics measurements and polarizationmodulation infrared reflection spectroscopy (PM-IRAS) characterizations, Gao et al. $^{26}$ reported that neither $\mathrm{Au}$ nor isolated Pd sites on the $\operatorname{AuPd}(100)$ surface are capable of dissociating oxygen molecules. Contiguous $\mathrm{Pd}$ sites are required for $\mathrm{O}_{2}$ dissociation, which in turn accounts for a high $\mathrm{CO}$ oxidation activity over the $\mathrm{AuPd}(110)$ surface. $^{26}$

In this study, we combine experimental and theoretical methods to investigate the activation of oxygen and its reaction with $\mathrm{CO}$ on $\mathrm{Pd} / \mathrm{Au}(111)$ bimetallic surfaces. The adsorption of oxygen molecules was studied by King-Wells measurements, in which an $\mathrm{O}_{2}$ beam was impinged onto a variety of $\mathrm{Pd} / \mathrm{Au}(111)$ surfaces at $77 \mathrm{~K}$. These surfaces were physically characterized employing Auger electron spectroscopy (AES) and reflectionabsorption infrared spectroscopy (RAIRS) using $\mathrm{CO}$ as a probe molecule. The interactions of oxygen admolecules with $\mathrm{Pd} /$ $\mathrm{Au}(111)$ surfaces (i.e., desorption and dissociation) were then investigated using $\mathrm{O}_{2}$-TPD. The energy for $\mathrm{O}_{2}$ desorption and energy barrier for $\mathrm{O}_{2}$ dissociation on $\mathrm{Pd} / \mathrm{Au}(111)$ surfaces with Pd ensembles of various sizes were calculated via DFT methods. CO-RMBS was used to probe the reactivity of oxygen species on $\mathrm{Pd} / \mathrm{Au}(111)$ surfaces by monitoring $\mathrm{CO}_{2}$ production. Finally, possible reaction mechanisms (i.e., associative and dissociative pathways) for $\mathrm{CO}$ oxidation on $\mathrm{Pd} / \mathrm{Au}(111)$ surfaces were discussed in terms of the $\mathrm{Pd}$ ensemble size using DFT calculations.

\section{EXPERIMENTAL AND COMPUTATIONAL METHODS}

UHV Experiments. All experiments in this study were performed in an UHV chamber that has been described in detail previously. ${ }^{40,41}$ Briefly, the chamber is equipped with an Auger electron spectrometer (Physical Electronics 10-500), a quadrupole mass spectrometer (Extrel C-50), and a Fourier transform infrared spectrometer (Bruker Tensor 27) combined with a mercury-cadmium-telluride (MCT) detector (Infrared Associates), as well as nozzles and apertures for generating two separate molecular beams.

The $\mathrm{Au}(111)$ single-crystal sample is a circular disk (Princeton Scientific, $12 \mathrm{~mm}$ in diameter $\times 2 \mathrm{~mm}$ thick) held in place by a Mo wire fitted around a groove cut into the side of the sample. This wire is also used to resistively heat the sample and provide thermal contact between the sample and a liquid nitrogen bath for cooling. The temperature of the sample was measured with a K-type (Alumel-Chromel) thermocouple placed into a small hole in the edge of the disk-shaped sample. The $\mathrm{Au}(111)$ surface was periodically cleaned by $\mathrm{Ar}$ ion bombardment $(2 \mathrm{keV})$, carried out at room temperature, followed by an anneal to $800 \mathrm{~K}$. The cleanliness of the surface was verified by AES with a beam energy of $3 \mathrm{keV}$ and emission current of $1.5 \mathrm{~mA}$.

$\mathrm{Pd}-\mathrm{Au}$ bimetallic model surfaces were prepared by depositing $\sim 2.9$ monolayer (ML) of $\mathrm{Pd}$ atoms from a homemade thermal evaporator onto the $\mathrm{Au}(111)$ surface at $77 \mathrm{~K}$ followed by annealing to a specified temperature for 10 min. ${ }^{42-44}$ The growth of the $\mathrm{Pd}$ overlayer on the $\mathrm{Au}(111)$ surface at $77 \mathrm{~K}$ is believed to obey a layer-by-layer mechanism, and upon annealing surface Pd atoms can diffuse into the bulk of the $\mathrm{Au}(111)$ surface, forming a $\mathrm{Pd}-\mathrm{Au}$ alloy at the surface. ${ }^{45}$
The deposition rate of $\mathrm{Pd}$ in this study was calibrated with a quartz crystal microbalance (QCM) controller (Maxtek Inc.) assuming the thickness of $1 \mathrm{ML}$ Pd equals $0.274 \mathrm{~nm}$.

The adsorption of oxygen molecules on $\mathrm{Pd}-\mathrm{Au}$ surfaces that were annealed to various temperatures (500-675 K) was investigated by King and Wells measurements. ${ }^{46-49}$ A neat $\mathrm{O}_{2}$ molecular beam with a translational energy of $\sim 0.1 \mathrm{eV}$ was first impinged on the stainless steel inert flag to establish a baseline. The beam was then impinged on the annealed $\mathrm{Pd} / \mathrm{Au}(111)$ surface at a surface temperature of $77 \mathrm{~K}$. The $\mathrm{O}_{2}$ QMS signal $\left(\mathrm{m} / \mathrm{z}^{+}=32\right)$ was monitored during the King-Wells measurements.

Reflection absorption infrared spectroscopy using $\mathrm{CO}$ as a probe molecule (CO-RAIRS) was used to characterize the annealed $\mathrm{Pd}-\mathrm{Au}$ surfaces. The $\mathrm{Pd}-\mathrm{Au}$ surface was first heated to $500 \mathrm{~K}$ at $1 \mathrm{~K} / \mathrm{s}$ to desorb any surface contaminants such as CO. After the sample had cooled to $77 \mathrm{~K}$, an IR background scan was taken. Saturation coverage of $\mathrm{CO}$ was dosed by a molecular beam of $\mathrm{CO}$ with the sample held at $77 \mathrm{~K}$. The IR spectrum of saturated $\mathrm{CO}$ adsorbed on the surface was taken at $77 \mathrm{~K}$. All spectra were averaged from 512 scans with a resolution of $4 \mathrm{~cm}^{-1}$.

For $\mathrm{O}_{2}-\mathrm{TPD}$ and $\mathrm{CO}-\mathrm{RMBS}$ experiments, the $\mathrm{Pd}-\mathrm{Au}$ bimetallic surface was generated by depositing 2.9 ML Pd on the $\mathrm{Au}(111)$ surface followed by annealing to $500 \mathrm{~K}$ for $10 \mathrm{~min}$. This surface consists of $\sim 77 \% \mathrm{Pd}$ and $\sim 23 \%$ Au based on lowenergy ion-scattering spectroscopy (LEISS) characterizations. ${ }^{45}$ In $\mathrm{O}_{2}$-TPD measurements, oxygen was dosed by impinging an $\mathrm{O}_{2}$ beam on the $\mathrm{Pd}-\mathrm{Au}$ surface at $77 \mathrm{~K}$. The surface was then heated at a rate of $1 \mathrm{~K} / \mathrm{s}$, while $m / z^{+}=32\left(\mathrm{O}_{2}\right)$ was monitored by QMS. For CO-RMBS experiments, the $\mathrm{Pd}-\mathrm{Au}$ surface was first saturated with oxygen at $77 \mathrm{~K}$ by backfilling the chamber with 1 langmuir $\left(\mathrm{L} ; 1 \mathrm{~L}=1 \times 10^{-6}\right.$ Torr-s) of $\mathrm{O}_{2}$ through a leak valve. The oxygen-precovered $\mathrm{Pd}-\mathrm{Au}$ surface was then heated to a specific temperature $(77-250 \mathrm{~K})$ prior to $\mathrm{CO}$ beam impingement. QMS signals of $m / z^{+}=32\left(\mathrm{O}_{2}\right), 44\left(\mathrm{CO}_{2}\right)$, and 28 ( $\mathrm{CO}$ ) were simultaneously monitored during CO-RMBS experiments.

DFT Calculations. All DFT calculations were performed with the Vienna ab initio simulation package..$^{50-53}$ The interaction between the ionic core and the valence electrons was described by the project augmented wave method, ${ }^{54}$ and the valence electrons were described with a plane-wave basis up to an energy cutoff of $300 \mathrm{eV}^{55,56}$ The energy cutoff was increased to $400 \mathrm{eV}$ to test for convergence, and the $\mathrm{O}_{2}$ dissociation barrier on $\mathrm{Au}$ was found to vary by less than 0.005 $\mathrm{eV}$. The exchange correlation contribution to the total energy functional was determined using the Perdew-Burke-Ernzerhof (PBE) generalized gradient approximation functional. ${ }^{57}$ The location and energy of the transition states were calculated with the climbing-image nudged elastic band method. ${ }^{58,59}$ The gold surface was modeled as a four-layer $4 \times 4 \mathrm{Au}(111)$ slab with the bottom two layers fixed and $10 \AA$ of vacuum. The Pd-decorated $\mathrm{Au}(111)$ surfaces in this study are modeled by replacing $\mathrm{Au}$ atoms on the top layer of the $\mathrm{Au}(111)$ slab with various $\mathrm{Pd}$ ensembles, as illustrated in Figure S1 (Supporting Information). The Brillouin zone was sampled using a $3 \times 3 \times 1$ Monkhorst-Pack k-point mesh. ${ }^{60}$ The convergence criteria for the electronic structure and the atomic geometry were $10^{-5} \mathrm{eV}$ and $0.01 \mathrm{eV} / \AA$, respectively. The binding energies of $\mathrm{O}_{2}$ and $\mathrm{CO}$ on the surface are referenced to the gas-phase $\mathrm{O}_{2}$ and $\mathrm{CO}$ molecules, respectively. 


\section{RESULTS AND DISCUSSION}

Adsorption of Oxygen on Pd-Au Surfaces. In this study, the adsorption of oxygen molecules on Pd-Au surfaces was investigated by King-Wells measurements. Figure 1 shows

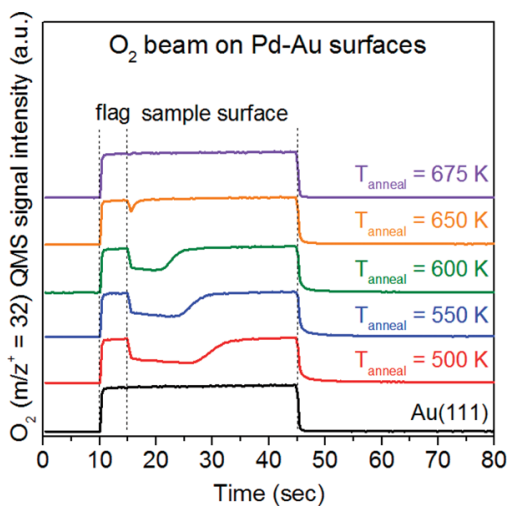

Figure 1. King-Wells measurements of an $\mathrm{O}_{2}$ beam impinging on $\mathrm{Au}(111)$ and annealed 2.9 $\mathrm{ML} \mathrm{Pd} / \mathrm{Au}(111)$ surfaces at a surface temperature of $77 \mathrm{~K}$.

the $\mathrm{O}_{2}$ QMS signal during a series of King-Wells measurements in which an $\mathrm{O}_{2}$ beam was impinged onto the $2.9 \mathrm{ML} \mathrm{Pd} /$ $\mathrm{Au}(111)$ surface that was previously annealed to various temperatures (i.e., 500-675 K). The $\mathrm{O}_{2}$ molecular beam was first impinged onto the inert flag that was held in front of the sample surface for $5 \mathrm{~s}$ (from 10 to $15 \mathrm{~s}$ ) to establish a baseline signal (all $\mathrm{O}_{2}$ molecules scattering from the inert flag). After removing the inert flag, the beam was impinged onto the Pd$\mathrm{Au}$ surface that was held at $77 \mathrm{~K}$ for $30 \mathrm{~s}$ (from 15 to $45 \mathrm{~s}$ ). The measurement was also conducted on the clean (Pd-free) $\mathrm{Au}(111)$ surface and is included for comparison.

When the $\mathrm{O}_{2}$ beam was impinged on the inert flag, a constant $\mathrm{O}_{2}$ QMS signal was detected due to scattering of the beam with negligible adsorption on the sample. After the removal of the inert flag, a constant $\mathrm{O}_{2}$ QMS signal was observed from the clean $\mathrm{Au}(111)$ surface, signifying no oxygen adsorption (or uptake) occurred on the clean $\mathrm{Au}(111)$ surface.

For the $\mathrm{Pd} / \mathrm{Au}(111)$ surface annealed to $500 \mathrm{~K}$, the intensity of the $\mathrm{O}_{2}$ QMS signal was initially lower than that observed for impingement onto the inert flag due to the adsorption of oxygen on the surface. Since no oxygen uptake was observed on the $\mathrm{Au}(111)$ surface, it is proposed that the adsorption sites for oxygen on the annealed $\mathrm{Pd} / \mathrm{Au}(111)$ surface consist of $\mathrm{Pd}$ surface atoms. It has been reported that with exposure to oxygen molecules at $100 \mathrm{~K}$ oxygen adsorbs molecularly on the $\operatorname{Pd}(111)$ surface, and the dissociation of oxygen admolecules occurs at temperatures of $\sim 180-200 \mathrm{~K}^{20}$ Accordingly, the oxygen adsorption on the $\mathrm{Pd}-\mathrm{Au}$ surface observed here is likely molecular adsorption without dissociation. The initial sticking probability of oxygen is $\sim 0.43$ for the $\mathrm{Pd} / \mathrm{Au}(111)$ surface annealed at $500 \mathrm{~K}$. The sticking probability eventually decreases to zero (where the intensity of the $\mathrm{O}_{2}$ QMS signal from the sample surface became nearly identical with that from the inert flag) as adsorbed oxygen saturated the $\mathrm{Pd}-\mathrm{Au}$ surface.

When the $\mathrm{Pd} / \mathrm{Au}(111)$ surface was progressively annealed to higher temperatures $(550-675 \mathrm{~K})$, the time to saturate the surface with oxygen molecules gradually reduced, indicative of less oxygen uptake since the flux of the $\mathrm{O}_{2}$ beam was kept constant for all of these measurements. The uptake of oxygen on each surface during the King-Wells measurements is proportional to the magnitude of integral of the intensity of the $\mathrm{O}_{2}$ QMS signal from the sample surface using the intensity of the $\mathrm{O}_{2}$ QMS signal from the inert flag as a baseline (Figure S2, Supporting Information). Relative to the $\mathrm{Pd} / \mathrm{Au}(111)$ surface annealed at $500 \mathrm{~K}$, the oxygen uptake for $\mathrm{Pd} / \mathrm{Au}(111)$ surfaces annealed to 550,600 , and $650 \mathrm{~K}$ reduced to $\sim 75 \%, 49 \%$, and $2 \%$, respectively. The oxygen uptake was negligible on the $\mathrm{Pd} /$ $\mathrm{Au}(111)$ surface that was annealed at $675 \mathrm{~K}$.

The oxygen uptake on the $\mathrm{Pd}-\mathrm{Au}$ surface is correlated with the concentration of surface Pd atoms. We characterized the relative surface compositions for annealed $\mathrm{Pd} / \mathrm{Au}(111)$ surfaces by AES. Figure S3 (Supporting Information) shows the AES spectra of as-prepared and annealed 2.9 ML $\mathrm{Pd} / \mathrm{Au}(111)$ surfaces. As the annealing temperature was increased, the $\mathrm{Pd}$ AES signal intensity was attenuated, and the Au AES signal intensity was enhanced, which has been previously observed by Koel and co-workers. ${ }^{45}$ This effect is attributed to diffusion of surface $\mathrm{Pd}$ atoms into the subsurface of the $\mathrm{Au}(111)$ singlecrystal sample during the annealing process. ${ }^{45}$ The oxygen uptake during King-Wells measurements as a function of the $\mathrm{Pd} / \mathrm{Au}$ AES signal intensity ratio of each annealed surface is illustrated in Figure 2.

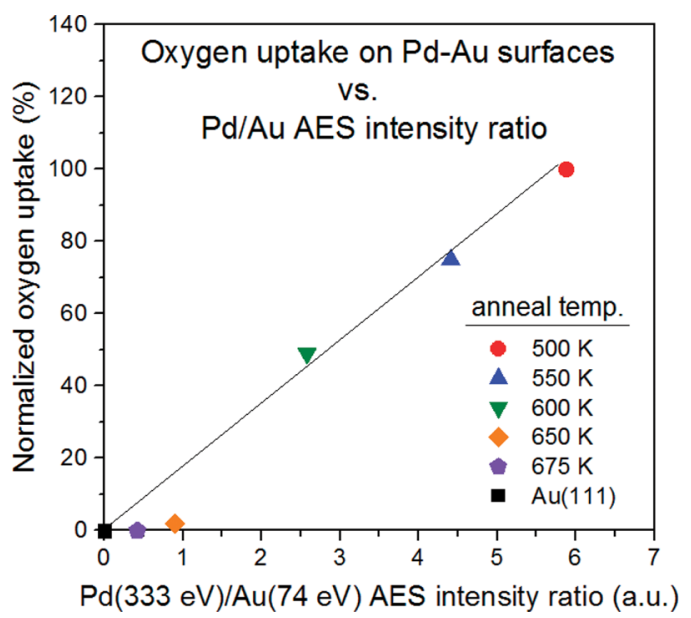

Figure 2. Oxygen uptake during King-Wells measurements on annealed 2.9 ML Pd/Au(111) bimetallic surfaces versus $\mathrm{Pd}(333 \mathrm{eV})$ / $\mathrm{Au}(74 \mathrm{eV})$ AES intensity ratio.

The oxygen uptake is linearly proportional to the $\mathrm{Pd} / \mathrm{Au} \mathrm{AES}$ signal intensity ratio for all surfaces except those that were annealed at 650 and $675 \mathrm{~K}$. This deviation suggests that other surface properties (e.g., arrangement of $\mathrm{Pd}$ and $\mathrm{Au}$ surface atoms) may also influence the oxygen uptake on the $\mathrm{Pd}-\mathrm{Au}$ surface, and oxygen uptake may not simply be a function of the concentration of $\mathrm{Pd}$ atoms on the $\mathrm{Pd} / \mathrm{Au}(111)$ surface.

The annealed $\mathrm{Pd} / \mathrm{Au}(111)$ surfaces were further characterized by RAIRS using $\mathrm{CO}$ as a probe molecule (CO-RAIRS). CO-RAIRS has been extensively employed to characterize the surface properties and structures of the $\mathrm{Pd}-\mathrm{Au}$ model surface. ${ }^{6,26,42,61-63}$ The type of adsorption site occupied by CO (e.g., atop sites, 2-fold or 3-fold bridge sites) can be inferred by the intramolecular $\mathrm{CO}$ stretch frequency $\left(\nu_{\mathrm{CO}}\right)$ as a result of varying degrees of $\pi$-antibonding back-donation from the surface electrons. ${ }^{64}$ Figure 3 shows the RAIRS spectra for saturated $\mathrm{CO}$ adsorbed on the clean $\mathrm{Au}(111)$ and annealed 2.9 $\mathrm{ML} \mathrm{Pd} / \mathrm{Au}(111)$ surfaces at $77 \mathrm{~K}$. 


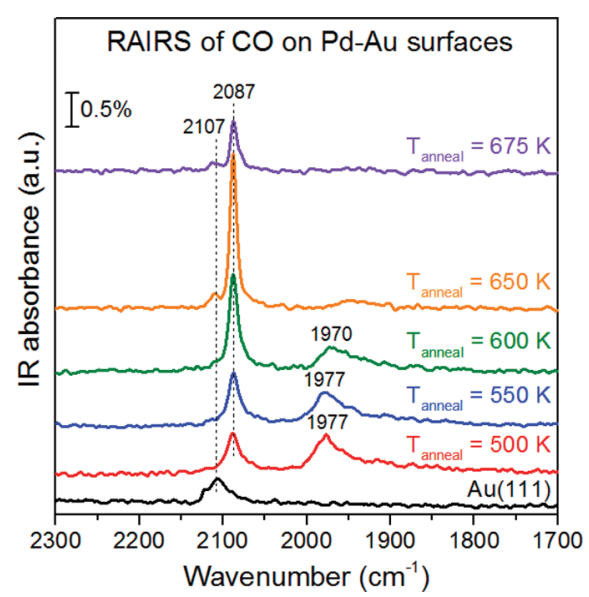

Figure 3. RAIRS spectra of saturated $\mathrm{CO}$ on $\mathrm{Au}(111)$ and annealed 2.9 $\mathrm{ML} \mathrm{Pd} / \mathrm{Au}(111)$ bimetallic surfaces taken at a surface temperature of $77 \mathrm{~K}$.

For the clean $\mathrm{Au}(111)$ surface, only one vibrational band at $\sim 2107 \mathrm{~cm}^{-1}$ was observed, which is associated with $\mathrm{CO}$ bound to atop $\mathrm{Au}$ sites. ${ }^{26,61-63,65} \mathrm{The} \mathrm{Pd} / \mathrm{Au}(111)$ surface annealed at $500 \mathrm{~K}$ displayed two IR features at $\sim 2087$ and $\sim 1977 \mathrm{~cm}^{-1}$, which have been assigned to atop $\mathrm{CO}$ on isolated Pd sites (or $\mathrm{Pd}$ monomer) and bridged $\mathrm{CO}$ on contiguous $\mathrm{Pd}$ sites, respectively. ${ }^{26,61-63}$ Increasing the annealing temperature resulted in the attenuation of the IR signal associated with bridged $\mathrm{CO}$ on contiguous Pd sites $\left(\nu_{\mathrm{CO}}=\sim 1977 \mathrm{~cm}^{-1}\right)$ and intensification of the signal associated with $\mathrm{CO}$ atop on isolated Pd sites $\left(\nu_{\mathrm{CO}}=\sim 2087 \mathrm{~cm}^{-1}\right)$. The IR band due to bridged CO on contiguous $\mathrm{Pd}$ sites became relatively small for the $\mathrm{Pd} /$ $\mathrm{Au}(111)$ surfaces annealed at $650 \mathrm{~K}$ and disappeared when annealed at $675 \mathrm{~K}$. Considering the CO-RAIRS spectra (Figure 3 ) and oxygen uptake (Figure 2), it suggests that the presence of contiguous $\mathrm{Pd}$ sites on the $\mathrm{Pd}-\mathrm{Au}$ surface is crucial for adsorption of oxygen molecules.

These experimental observations are conceptually consistent with our DFT calculations of oxygen adsorption. The binding energy of an oxygen molecule as a function of $\mathrm{Pd}$ ensemble size on $\mathrm{Pd} / \mathrm{Au}(111)$ surfaces is presented in Figure S4 (Supporting Information). As shown in the inset of Figure S4 (Supporting Information), molecular oxygen binds on the fcc hollow site aligned in a top-hollow-bridge ( $t-h-b)$ geometry on these surfaces, except for the $\mathrm{Pd}_{2}-\mathrm{Au}(111)$ surface, where the oxygen molecule bridges on two Pd atoms. The calculated binding energy for the oxygen molecule on the $\mathrm{Au}(111)$ surface is 0.34 $\mathrm{eV}$. With the presence of the Pd monomer, the binding energy decreases to $0.11 \mathrm{eV}$ on the $\mathrm{Pd}_{1}-\mathrm{Au}(111)$ surface. These positive values of binding energy indicate that the adsorption of an oxygen molecule is energetically unfavorable on the clean $\mathrm{Au}(111)$ and $\mathrm{Pd}_{1}-\mathrm{Au}(111)$ surfaces. The binding energy of the oxygen molecule reduces to the negative value of $-0.17 \mathrm{eV}$ on the $\mathrm{Au}(111)$ surface with a $\mathrm{Pd}$ dimer (i.e., $\mathrm{Pd}_{2}-\mathrm{Au}(111)$ surface), which supports our experimental observation of the importance of contiguous Pd sites for adsorption of oxygen molecules on the $\mathrm{Pd}-\mathrm{Au}$ surface. These results are also consistent with previous DFT reports, in which the effects of Pd ensembles (i.e., monomer, dimer, and trimer) on the adsorption oxygen molecule were investigated using $1 \mathrm{ML} \mathrm{Au} /$ $\mathrm{Pd}(111)^{29}$ and $\mathrm{Au}(111)$ surfaces $^{35}$ as substrates. The binding energy of the oxygen molecule on the $\mathrm{Pd} / \mathrm{Au}(111)$ surface gradually decreases as the $\mathrm{Pd}$ ensemble size increases. For the
$\mathrm{Au}(111)$ surfaces fully covered by $1 \mathrm{ML}$ of Pd overlayer, the calculated binding energy of the oxygen molecule is $-0.83 \mathrm{eV}$, indicating that the oxygen molecule binds more strongly to this surface than to other $\mathrm{Pd} / \mathrm{Au}(111)$ surfaces.

Desorption of Oxygen from Pd-Au Surfaces. The interaction of oxygen with the $\mathrm{Pd}-\mathrm{Au}$ surface was investigated via $\mathrm{O}_{2}$-TPD as shown in Figure 4. The $\mathrm{Pd}-\mathrm{Au}$ surface was

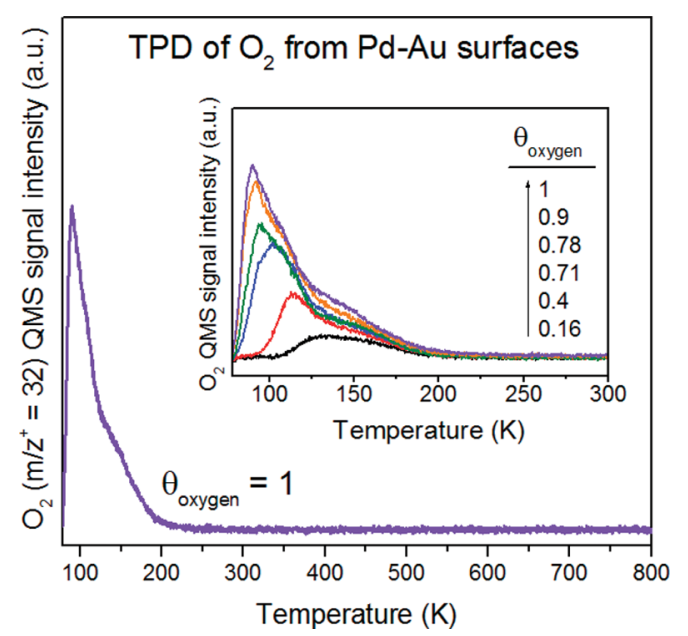

Figure 4. TPD of saturated $\mathrm{O}_{2}$ from the $\mathrm{Pd} / \mathrm{Au}(111)$ bimetallic surface. Inset shows the TPD of various coverages of $\mathrm{O}_{2}$ from the same surface. The heating rate was $1 \mathrm{~K} / \mathrm{s}$.

generated by depositing 2.9 ML Pd onto the $\mathrm{Au}(111)$ surface at $77 \mathrm{~K}$ followed by annealing at $500 \mathrm{~K}$. Dosing of $\mathrm{O}_{2}$ was achieved by impinging a molecular beam of $\mathrm{O}_{2}$ onto the surface at $77 \mathrm{~K}$ prior to heating.

$\mathrm{O}_{2}$-TPD has been extensively studied on the $\mathrm{Pd}(111)$ surface. ${ }^{17,18,20,21}$ According to the desorption temperature, two types of oxygen desorption processes have been identified from the $\operatorname{Pd}(111)$ surface: ${ }^{20}$ associative desorption (or recombinative desorption of oxygen adatoms; peak temperature at $\sim 800 \mathrm{~K}$ ) and molecular desorption (or direct desorption of oxygen admolecules; peak temperatures at $\sim 200,150$, and $125 \mathrm{~K}$ ). In Figure 4 , the oxygen desorption peak ended at $\sim 220 \mathrm{~K}$, and no other feature was observed during heating to $800 \mathrm{~K}$. These results suggest that oxygen admolecules desorb molecularly from the $\mathrm{Pd}-\mathrm{Au}$ surface without detectable dissociation into oxygen adatoms. It is noted that the $\mathrm{Pd} / \mathrm{Au}(111)$ surface that was generated by annealing at $500 \mathrm{~K}$ undergoes significant changes when the temperature is heated to above $500 \mathrm{~K}$ (as shown in AES (Figure S3, Supporting Information) and CORAIRS (Figure 3) characterizations), which increases the difficulty of investigating the phenomena for recombinative desorption of oxygen adatoms during heating. Nevertheless, it is clear that the surface concentration of oxygen adatoms from dissociation of oxygen molecules (if any) is not sufficient to detect via $\mathrm{O}_{2}$-TPD. The inset in Figure 4 shows desorption of oxygen molecules with various coverages from the $\mathrm{Pd}-\mathrm{Au}$ surface. In these TPD measurements, various coverages of oxygen were dosed onto the same $\mathrm{Pd}-\mathrm{Au}$ surface at $77 \mathrm{~K}$ followed by heating to $500 \mathrm{~K}$. To more clearly visualize desorption peaks, the obtained spectra were plotted within the temperature range between 77 and $300 \mathrm{~K}$ (no oxygen desorption was observed when the temperature was higher than $300 \mathrm{~K}$ ) as shown in the inset of Figure 4. In contrast with the sharp features in molecular oxygen desorption observed 
from the $\mathrm{Pd}(111)$ surface $^{20}$ the desorption peaks for oxygen molecules from the $\mathrm{Pd}-\mathrm{Au}$ surface are relatively broad, which is likely due to the relatively high degree of heterogeneity of the annealed $\mathrm{Pd} / \mathrm{Au}(111)$ surface in comparison to that of the $\operatorname{Pd}(111)$ surface.

The competition between desorption and dissociation of the molecular oxygen on $\mathrm{Pd}-\mathrm{Au}$ surfaces upon heating was also explored by DFT calculations. Figure 5 represents the energy

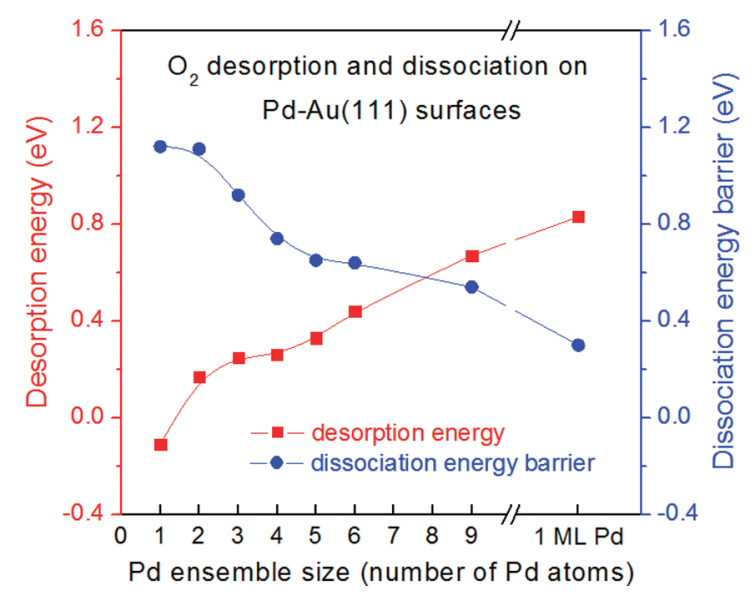

Figure 5. Energy for desorption and energy barrier for dissociation of an oxygen molecule adsorbed on $\mathrm{Pd} / \mathrm{Au}(111)$ surfaces as determined by DFT calculations.

for desorption and energy barrier for dissociation of an oxygen molecule on $\mathrm{Pd} / \mathrm{Au}(111)$ surfaces as a function of $\mathrm{Pd}$ ensemble size. The corresponding potential energy diagram is shown in Figure S5 (Supporting Information). It is noted that the energy for desorption of the oxygen admolecule is essentially the negative value of the binding energy shown in Figure S4 (Supporting Information).

As shown in Figure 5, the energy for desorption of an oxygen admolecule (i.e., $\mathrm{O}_{2(\mathrm{ad})} \rightarrow \mathrm{O}_{2(\mathrm{~g})}$ ) gradually increases from 0.17 to $0.44 \mathrm{eV}$ as the $\mathrm{Pd}$ ensemble on the $\mathrm{Au}(111)$ surface changes from a dimer to a hexamer. On the other hand, the energy barrier for dissociation of an oxygen admolecule (i.e., $\mathrm{O}_{2(\mathrm{ad})} \rightarrow$ $\left.2 \mathrm{O}_{(\mathrm{ad})}\right)$ decreases from 1.11 to $0.64 \mathrm{eV}$ under the same conditions. It is noted that the energy for desorption is smaller than the energy barrier for dissociation on each of these $\mathrm{Pd} /$ $\mathrm{Au}(111)$ surfaces. Furthermore, it has been reported that the desorption prefactor $\left(\nu_{\text {des }}\right)$ is usually significantly larger than the dissociation prefactor $\left(\nu_{\text {diss }}\right)$ for a molecular adsorbate $\left(\nu_{\text {diss }}\right.$ $\left.=\sim 10^{-3} \nu_{\text {des }}\right){ }^{66}$ Accordingly, desorption of $\mathrm{O}_{2}$ is favored over its dissociation on these $\mathrm{Pd} / \mathrm{Au}(111)$ surfaces. In other words, upon heating, the oxygen admolecule would prefer to desorb from the surface at the temperature below its dissociation temperature. These results are in good agreement with our $\mathrm{O}_{2}$ TPD observations (Figure 4), in which molecular desorption of oxygen was observed, but the recombinative desorption of atomic oxygen that comes from dissociation was undetectable. As shown in Figure 5, the dissociation of an oxygen admolecule becomes energetically favorable over desorption when larger $\mathrm{Pd}$ ensembles (e.g., consisting of nine Pd atoms) are present on the $\mathrm{Au}(111)$ surface. For the $\mathrm{Au}(111)$ surface covered by $1 \mathrm{ML}$ of $\mathrm{Pd}$ (i.e., the $\mathrm{Pd}_{1 \mathrm{ML}} / \mathrm{Au}(111)$ surface), the calculated energy barrier for dissociation of an oxygen admolecule $(0.3 \mathrm{eV})$ is much lower than the energy for desorption of an oxygen admolecule $(0.83 \mathrm{eV})$. This is consistent with the observation that low coverages of oxygen admolecules can completely dissociate into oxygen adatoms on the $\mathrm{Pd}(111)$ surface. $^{20}$

Reaction of Oxygen and $\mathrm{CO}$ on Pd-Au Surfaces. The reaction with $\mathrm{CO}$ to form $\mathrm{CO}_{2}$ has been used to experimentally probe the reactivity of surface oxygen on $\mathrm{Pd}-\mathrm{Au}$ model surfaces. $^{25-27}$ In this study, the reactivity of molecular oxygen adsorbed on the $\mathrm{Pd} / \mathrm{Au}(111)$ surface upon heating was assessed by $\mathrm{CO}-\mathrm{RMBS}$ via monitoring $\mathrm{CO}_{2}$ production. $\mathrm{CO}$ RMBS experiments were conducted by impinging a molecular beam of $\mathrm{CO}$ onto the inert flag for $5 \mathrm{~s}$ (from 15 to $20 \mathrm{~s}$ ) and then onto the molecular oxygen-precovered $\mathrm{Pd}-\mathrm{Au}$ surface for $60 \mathrm{~s}$ (from 20 to $80 \mathrm{~s}$ ) as shown in Figure 6. For these
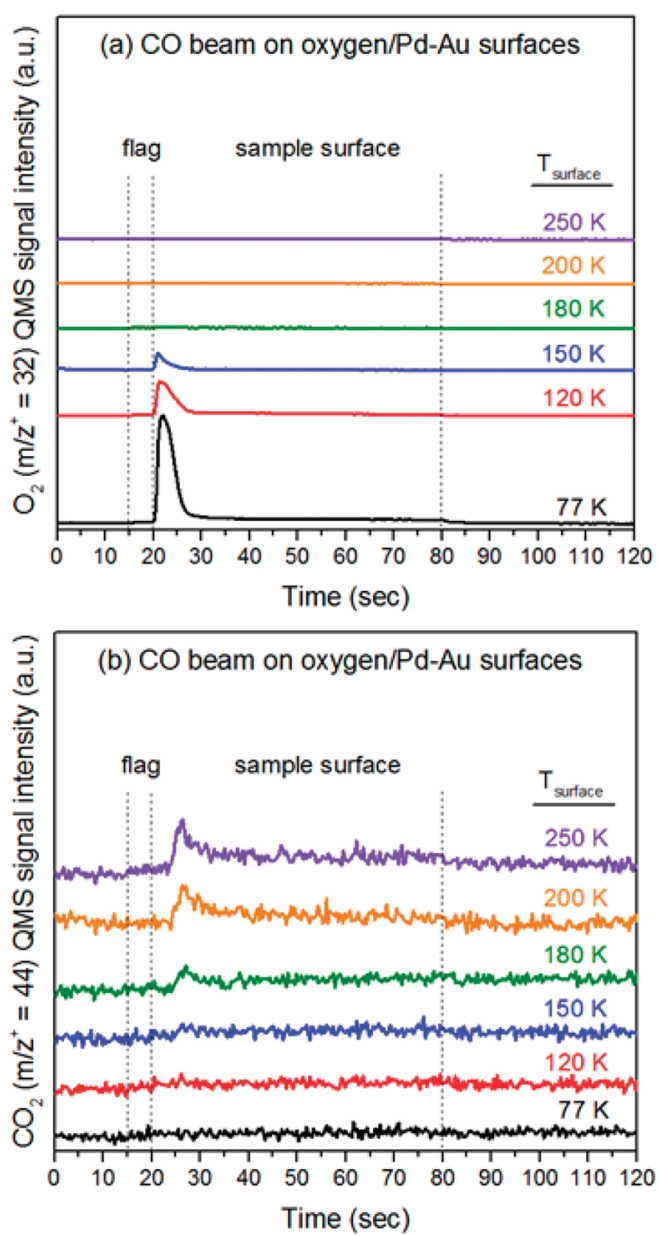

Figure 6. (a) $\mathrm{O}_{2}\left(m / z^{+}=32\right)$ and (b) $\mathrm{CO}_{2}\left(m / z^{+}=44\right)$ QMS signals during CO-RMBS on the oxygen-presaturated $\mathrm{Pd} / \mathrm{Au}(111)$ bimetallic surface at various surface temperatures.

measurements, the Pd-Au surface (generated by depositing 2.9 $\mathrm{ML} \mathrm{Pd}$ onto the $\mathrm{Au}(111)$ surface at $77 \mathrm{~K}$ followed by annealing at $500 \mathrm{~K}$ ) was presaturated with molecular oxygen at $77 \mathrm{~K}$ and then heated to a specific temperature $(77-250 \mathrm{~K})$ prior to $\mathrm{CO}$ beam impingement. The measured $\mathrm{O}_{2}$ and $\mathrm{CO}_{2}$ QMS signals are depicted in Figures $6 \mathrm{a}$ and $6 \mathrm{~b}$, respectively.

As expected, neither $\mathrm{O}_{2}$ nor $\mathrm{CO}_{2}$ QMS signals were detected when the $\mathrm{CO}$ beam was impinged onto the inert flag. When the $\mathrm{CO}$ beam struck the oxygen-precovered $\mathrm{Pd}-\mathrm{Au}$ surface at 77 $\mathrm{K}$, a peak in the $\mathrm{O}_{2}$ QMS signal emerged (Figure 6a), indicating that impingement of $\mathrm{CO}$ onto the surface caused evolution of $\mathrm{O}_{2}$. This $\mathrm{O}_{2}$ evolution is likely due to the competitive adsorption of $\mathrm{CO}$ on the surface sites, which displaces the 
preadsorbed $\mathrm{O}_{2}$ into the gas phase. Since no measurable $\mathrm{O}_{2}$ adsorption was detected when an $\mathrm{O}_{2}$ beam struck the COpresaturated $\mathrm{Pd}-\mathrm{Au}$ surface at $77 \mathrm{~K}$ (Figure S6, Supporting Information), we speculate that the adsorption strength of $\mathrm{CO}$ on the surface is much stronger than that of $\mathrm{O}_{2}$. This suggestion is also supported by DFT calculations in which the binding of $\mathrm{CO}$ (Figure S7, Supporting Information) to $\mathrm{Pd} / \mathrm{Au}(111)$ surfaces is found to be stronger relative to that of $\mathrm{O}_{2}$ (Figure S4, Supporting Information). The oxygen evolution decreased in intensity when the $\mathrm{Pd}-\mathrm{Au}$ surface was preheated to $120 \mathrm{~K}$, which is likely due to desorption of $\mathrm{O}_{2}$ during heating (Figure 4) before $\mathrm{CO}$ beam impingement. The intensity of oxygen evolution decreased further as the surface was preheated and held at higher temperatures $(180-250 \mathrm{~K})$.

As shown in Figure 6b, no $\mathrm{CO}_{2}$ signal was detected when the $\mathrm{CO}$ beam was impinged onto the oxygen-precovered $\mathrm{Pd}-\mathrm{Au}$ surface held at temperatures ranging from 77 to $150 \mathrm{~K}$. These results show that the surface oxygen species is inactive to react with $\mathrm{CO}$ to form $\mathrm{CO}_{2}$ within this temperature range (77-150 $\mathrm{K})$. A small peak in $\mathrm{CO}_{2}$ production was observed when the $\mathrm{CO}$ beam struck the oxygen-precovered $\mathrm{Pd}-\mathrm{Au}$ surface at 180 $\mathrm{K}$, suggestive of the thermal activation of adsorbed oxygen molecules. It is noted that the $\mathrm{CO}_{2}$ peak emerged at $\sim 24 \mathrm{~s}$, which is $\sim 4 \mathrm{~s}$ after $\mathrm{CO}$ beam impingement which began at $20 \mathrm{~s}$. This is likely due to the site blocking from oxygen and hydrogen impurities (from adsorption of background gas that is intrinsically present in our UHV chamber) ${ }^{42}$ on the $\mathrm{Pd}-\mathrm{Au}$ surface. Figure S8 (Supporting Information) shows the QMS signals of $\mathrm{O}_{2}, \mathrm{CO}_{2}, \mathrm{H}_{2}$, and $\mathrm{CO}$ during a CO-RMBS experiment at $180 \mathrm{~K}$. The emergence of a $\mathrm{CO}_{2}$ production peak was observed after the evolution of $\mathrm{O}_{2}$ and $\mathrm{H}_{2}$ that were induced by $\mathrm{CO}$ beam impingement. The phenomena of $\mathrm{CO}$ induced recombinative desorption of $\mathrm{H}$ adatoms from the $\mathrm{Pd} /$ $\mathrm{Au}(111)$ surface have been observed previously. ${ }^{43}$

The $\mathrm{CO}_{2}$ production peak became more significant when the surface was heated to higher temperatures (200 and $250 \mathrm{~K}$ ) prior to $\mathrm{CO}$ beam impingement. As shown in Figure 4, the process for molecular desorption of adsorbed oxygen ended at a temperature of $\sim 220 \mathrm{~K}$. Accordingly, the $\mathrm{CO}_{2}$ production from the $\mathrm{Pd}-\mathrm{Au}$ surface observed at $250 \mathrm{~K}$ is likely due to the reaction of $\mathrm{CO}$ with oxygen adatoms rather than oxygen admolecules. This observation suggests that dissociation of oxygen admolecules could occur on the $\mathrm{Pd}-\mathrm{Au}$ surface during heating (the amount of oxygen that reacted with $\mathrm{CO}$ above 200 $\mathrm{K}$ is estimated as $\sim 0.3 \%$ of saturation oxygen coverage), which was undetected in the $\mathrm{O}_{2}$-TPD measurements in Figure 4. It is noted that oxygen admolecules dissociate into oxygen adatoms on the $\mathrm{Pd}(111)$ surface at $\sim 180-200 \mathrm{~K},{ }^{19-21}$ which is coincident with the temperature range in which we observed $\mathrm{CO}_{2}$ production from the reaction of $\mathrm{CO}$ with oxygen species on the $\mathrm{Pd}-\mathrm{Au}$ surface in CO-RMBS experiments (Figure $6 \mathrm{~b}$ ).

DFT calculations were performed to examine the influence of the $\mathrm{Pd}$ ensemble size on the reaction mechanism of $\mathrm{CO}$ oxidation on $\mathrm{Pd}-\mathrm{Au}$ surfaces. In this study, we consider two possible Langmuir-Hinshelwood mechanisms, i.e., dissociative and associative mechanisms, as shown in Scheme $1 .^{33}$

The dissociative and associative mechanisms are different from each other in regards to their initial step. For the dissociative mechanism, the $\mathrm{O}_{2}$ admolecule dissociates into $\mathrm{O}$ adatoms as the first step (step A). In the associative mechanism, the first step is the bimolecular reaction between the $\mathrm{O}_{2}$ admolecule and adsorbed $\mathrm{CO}$ to form adsorbed $\mathrm{CO}_{2}$ and an $\mathrm{O}$ adatom (step $\mathrm{C}$ ). The dissociative and associative
Scheme 1. Potential Dissociative and Associative Mechanisms for the Reaction of Oxygen with $\mathrm{CO}$ to Form $\mathrm{CO}_{2}{ }^{33}$

\begin{tabular}{|c|c|}
\hline issociative mechanism & \\
\hline $\begin{array}{l}\mathrm{O}_{2(\mathrm{ad})} \rightarrow 2 \mathrm{O}_{(\mathrm{ad})} \\
\mathrm{O}_{(\mathrm{ad})}+\mathrm{CO}_{(\mathrm{ad})} \rightarrow \mathrm{CO}_{2(\mathrm{ad})}\end{array}$ & $\begin{array}{l}\text { (A) } \\
\text { (B) }\end{array}$ \\
\hline Associative mechanism & \\
\hline $\begin{array}{l}\mathrm{O}_{2(\mathrm{ad})}+\mathrm{CO}_{(\mathrm{ad})} \rightarrow \mathrm{CO}_{2(\mathrm{ad})}+\mathrm{O}_{(\mathrm{ad})} \\
\mathrm{O}_{(\mathrm{ad})}+\mathrm{CO}_{(\mathrm{ad})} \rightarrow \mathrm{CO}_{2(\mathrm{ad})}\end{array}$ & \\
\hline
\end{tabular}

mechanisms result in the same overall reaction as the second step (step B); i.e., the $\mathrm{O}$ adatom reacts with adsorbed $\mathrm{CO}$ to form adsorbed $\mathrm{CO}_{2}{ }^{33}$

Figure 7 shows the calculated energy barriers for each step in the dissociative and associative $\mathrm{CO}$ oxidation on $\mathrm{Pd} / \mathrm{Au}(111)$

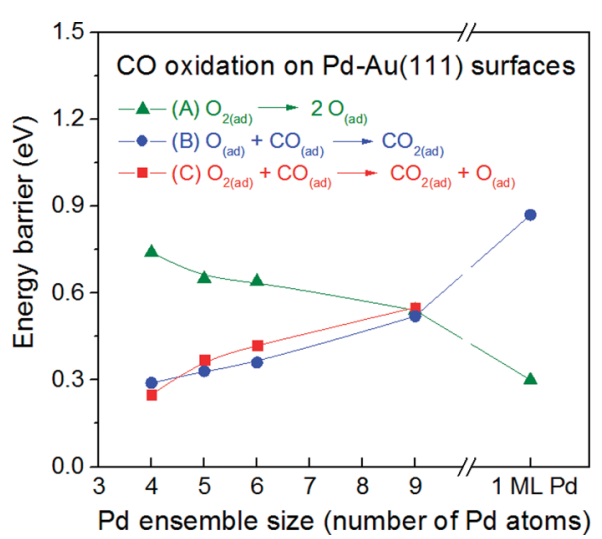

Figure 7. Energy barriers for dissociative and associative $\mathrm{CO}$ oxidation on $\mathrm{Pd} / \mathrm{Au}(111)$ surfaces as determined by DFT calculations.

surfaces. The corresponding reaction enthalpies are summarized in Table S1 (Supporting Information). It is noted that the $\mathrm{Pd}-\mathrm{Au}$ surfaces with a Pd ensemble size of less than four atoms are excluded due to the lack of a capacity for $\mathrm{CO}$ and $\mathrm{O}_{2}$ coadsorption. The initial, transition, and final state configurations on each surface are similar; accordingly, only those on the $\mathrm{Pd}_{6}-\mathrm{Au}(111)$ surface are illustrated in Figure $\mathrm{S} 9$ (Supporting Information) as an example.

On the $\mathrm{Pd}_{4}-\mathrm{Au}(111)$ surface, the energy barriers for $\mathrm{O}_{2(\mathrm{ad})}$ $\rightarrow 2 \mathrm{O}_{(\mathrm{ad})}\left(\right.$ step A), $\mathrm{O}_{(\mathrm{ad})}+\mathrm{CO}_{(\mathrm{ad})} \rightarrow \mathrm{CO}_{2(\mathrm{ad})}$ (step B), and $\mathrm{O}_{2(\mathrm{ad})}+\mathrm{CO}_{(\mathrm{ad})} \rightarrow \mathrm{CO}_{2(\mathrm{ad})}+\mathrm{O}_{(\mathrm{ad})}($ step C) are 0.74, 0.29, and $0.25 \mathrm{eV}$, respectively. These results suggest that associative $\mathrm{CO}$ oxidation is favorable on this surface, whereas dissociative $\mathrm{CO}$ oxidation is inhibited by a higher energy barrier for dissociating the $\mathrm{O}_{2}$ admolecule. It is worth mentioning that the energy for $\mathrm{O}_{2}$ desorption on the $\mathrm{Pd}_{4}-\mathrm{Au}(111)$ surface is $0.26 \mathrm{eV}$ (Figure $5)$, which is comparable to the reaction barriers for $\mathrm{O}_{(\mathrm{ad})}+$ $\mathrm{CO}_{(\mathrm{ad})} \rightarrow \mathrm{CO}_{2(\mathrm{ad})}\left(\right.$ step B) and $\mathrm{O}_{2(\mathrm{ad})}+\mathrm{CO}_{(\mathrm{ad})} \rightarrow \mathrm{CO}_{2(\mathrm{ad})}+$ $\mathrm{O}_{(\mathrm{ad})}($ step C).

As the Pd ensemble size increases, the energy barrier for $\mathrm{O}_{2}$ dissociation (step A) reduces, while energy barriers for $\mathrm{O}_{(\mathrm{ad})}+$ $\mathrm{CO}_{(\mathrm{ad})} \rightarrow \mathrm{CO}_{2(\mathrm{ad})}$ (step B) and $\mathrm{O}_{2(\mathrm{ad})}+\mathrm{CO}_{(\mathrm{ad})} \rightarrow \mathrm{CO}_{2(\mathrm{ad})}+$ $\mathrm{O}_{(\mathrm{ad})}$ (step $\mathrm{C}$ ) both increase. These energy barriers become comparable on the $\mathrm{Pd}_{9}-\mathrm{Au}(111)$ surface, which suggests that $\mathrm{CO}$ oxidation could proceed via both associative and dissociative pathways on this surface. As mentioned earlier, the dominant oxygen species on the $\mathrm{Pd}_{1 \mathrm{ML}}-\mathrm{Au}(111)$ surface is the $\mathrm{O}$ adatom rather than the $\mathrm{O}_{2}$ admolecule due to a lower energy barrier for $\mathrm{O}_{2}$ dissociation. Accordingly, dissociative $\mathrm{CO}$ 
oxidation is favorable on the $\mathrm{Pd}_{1 \mathrm{ML}}-\mathrm{Au}(111)$ surface, which is consistent with the experimental observations from the $\operatorname{Pd}(111)$ surface. ${ }^{67-71}$

On the basis of these DFT calculations, a generalization regarding the effect of $\mathrm{Pd}$ ensemble size on oxygen activation and reaction with $\mathrm{CO}$ was derived as follows: for the $\mathrm{Pd}-\mathrm{Au}$ surface containing small $\mathrm{Pd}$ ensembles, $\mathrm{O}_{2}$ desorption and associative $\mathrm{CO}$ oxidation are the two major competing processes, whereas the pathway for dissociative $\mathrm{CO}$ oxidation is limited by a high energy barrier for $\mathrm{O}_{2}$ dissociation. On the $\mathrm{Pd}-\mathrm{Au}$ surface with bigger $\mathrm{Pd}$ ensembles, the oxygen admolecule dissociates readily and, in turn, promotes $\mathrm{CO}_{2}$ formation via the dissociative $\mathrm{CO}$ oxidation pathway. It is wellaccepted that $\mathrm{CO}$ oxidation occurs on the $\mathrm{Pd}(111)$ surface via a dissociative pathway, ${ }^{67-71}$ in which chemisorbed $\mathrm{CO}$ reacts with dissociatively adsorbed oxygen to form $\mathrm{CO}_{2}$. DFT calculations in this study and previous reports ${ }^{32,35}$ suggest that $\mathrm{CO}$ oxidation could also occur through an associative mechanism on the $\mathrm{Pd}-\mathrm{Au}$ surface containing small $\mathrm{Pd}$ ensembles. Nevertheless, it is noted that an associative pathway was not experimentally supported in this study (Figure 6b), in which no $\mathrm{CO}_{2}$ production was detected when the $\mathrm{CO}$ beam was impinged onto the molecular oxygen-precovered $\mathrm{Pd}-\mathrm{Au}$ surface at and below $150 \mathrm{~K}$. This absence of $\mathrm{CO}_{2}$ production can be explained by the facile $\mathrm{CO}$-induced displacement of $\mathrm{O}_{2}$ (Figure 6a) due to significantly higher binding energies of $\mathrm{CO}$ relative to those of $\mathrm{O}_{2}$ (Figures $\mathrm{S} 4$ and S7, Supporting Information), which inhibits $\mathrm{CO}$ oxidation from proceeding via associative mechanism.

\section{CONCLUSION}

A model catalyst study combining UHV experiments and DFT calculations was performed to investigate the activation and reaction of oxygen molecules on the $\mathrm{Pd}-\mathrm{Au}$ surface. Results based on $\mathrm{O}_{2}$ King-Wells, CO-RAIRS, and DFT show that the presence of contiguous $\mathrm{Pd}$ sites is essential for adsorption of oxygen molecules on the $\mathrm{Pd}-\mathrm{Au}$ surface. Upon heating, the adsorbed oxygen molecules molecularly desorbed from the $\mathrm{Pd}-\mathrm{Au}$ surface $(<220 \mathrm{~K})$ without detectable dissociation (signified by a lack of recombinative desorption of oxygen atoms) in $\mathrm{O}_{2}$-TPD experiments. DFT calculations show that as the Pd ensemble size increases on the $\mathrm{Pd} / \mathrm{Au}(111)$ surface the energy for $\mathrm{O}_{2}$ desorption increases, and the energy barrier for $\mathrm{O}_{2}$ dissociation decreases. Oxygen molecules adsorbed on the $\mathrm{Pd} / \mathrm{Au}(111)$ surface were readily displaced by $\mathrm{CO}$ at lower temperatures $(77-150 \mathrm{~K})$ due to competitive adsorption on surface sites. The adsorbed oxygen molecule can be thermally activated at higher temperatures $(180-250 \mathrm{~K})$ to react with $\mathrm{CO}$ to form $\mathrm{CO}_{2}$. On the basis of DFT calculations, dissociative $\mathrm{CO}$ oxidation is favorable on the $\mathrm{Pd}-\mathrm{Au}$ surface containing larger Pd ensembles; for the $\mathrm{Pd}-\mathrm{Au}$ surface containing small $\mathrm{Pd}$ ensembles, associative $\mathrm{CO}$ oxidation and $\mathrm{O}_{2}$ desorption are the two competing processes that are both favored over dissociative $\mathrm{CO}$ oxidation. In this study, an associative $\mathrm{CO}$ oxidation mechanism was not experimentally observed on the $\mathrm{Pd}-\mathrm{Au}$ surface, which could be attributed to the fact that weakly bound $\mathrm{O}_{2}$ desorbs readily by $\mathrm{CO}$ displacement at low temperatures. We hope the findings in this study will assist in the future design of $\mathrm{Pd}-\mathrm{Au}$ bimetallic catalysts and their applications to associated reactions.

\section{ASSOCIATED CONTENT}

\section{Supporting Information}

Additional information regarding $\mathrm{Pd} / \mathrm{Au}(111)$ surfaces for DFT calculations, $\mathrm{O}_{2}$ King-Wells measurements for annealed $\mathrm{Pd} / \mathrm{Au}(111)$ surfaces, AES characterizations for as-deposited and annealed $\mathrm{Pd} / \mathrm{Au}(111)$ surfaces, binding energies for $\mathrm{O}_{2}$ on $\mathrm{Pd} / \mathrm{Au}(111)$ surfaces, potential energy diagram for $\mathrm{O}_{2}$ desorption and dissociation on $\mathrm{Pd} / \mathrm{Au}(111)$ surfaces, $\mathrm{O}_{2}$ King-Wells measurement for the CO-presaturated $\mathrm{Pd} /$ $\mathrm{Au}(111)$ surface, binding energies for $\mathrm{CO}$ on $\mathrm{Pd} / \mathrm{Au}(111)$ surfaces, $\mathrm{CO}-\mathrm{RMBS}$ on oxygen-precovered $\mathrm{Pd} / \mathrm{Au}(111)$ surface, dissociative and associative $\mathrm{CO}$ oxidation on $\mathrm{Pd} / \mathrm{Au}(111)$ surfaces; illustration of $\mathrm{Pd} / \mathrm{Au}(111)$ surfaces considered in DFT calculations; $\mathrm{O}_{2}$ uptake on annealed $\mathrm{Pd} / \mathrm{Au}(111)$ surfaces during $\mathrm{O}_{2}$ King-Wells measurements; AES spectra for asdeposited and annealed 2.9 ML Pd/Au(111) surface; calculated binding energies of $\mathrm{O}_{2}$ on $\mathrm{Pd} / \mathrm{Au}(111)$ surfaces; predicted potential energy diagram for $\mathrm{O}_{2}$ desorption and dissociation on $\mathrm{Pd} / \mathrm{Au}(111)$ surfaces; $\mathrm{O}_{2}$ QMS signal during $\mathrm{O}_{2}$ King-Wells measurement on $\mathrm{CO}$-presaturated $\mathrm{Pd} / \mathrm{Au}(111)$ surface; calculated binding energies of $\mathrm{CO}$ on $\mathrm{Pd} / \mathrm{Au}(111)$ surfaces; QMS signals during CO-RMBS on oxygen-precovered $\mathrm{Pd} / \mathrm{Au}(111)$ surfaces at $180 \mathrm{~K}$; calculated enthalpies and initial, transition, and final state configurations for associative and dissociative $\mathrm{CO}$ oxidation on $\mathrm{Pd} / \mathrm{Au}(111)$ surfaces. The Supporting Information is available free of charge on the ACS Publications website at DOI: 10.1021/acs.jpcc.5b02970.

\section{AUTHOR INFORMATION}

\section{Corresponding Author}

*E-mail: mullins@che.utexas.edu. Phone: 1-512-471-5817.

\section{Notes}

The authors declare no competing financial interest.

\section{ACKNOWLEDGMENTS}

We are thankful for the generous support of the Department of Energy (DE-FG02-04ER15587 and DE-FG02-13ER16428) and the Welch Foundation (Grants F-1436 for C.B.M. and F1841 for G.H.). G.M.M. thanks the National Science Foundation for a Graduate Research Fellowship.

\section{REFERENCES}

(1) Chen, J. G.; Menning, C. A.; Zellner, M. B. Monolayer Bimetallic Surfaces: Experimental and Theoretical Studies of Trends in Electronic and Chemical Properties. Surf. Sci. Rep. 2008, 63, 201-254.

(2) Gao, F.; Goodman, D. W. Pd-Au Bimetallic Catalysts: Understanding Alloy Effects from Planar Models and (Supported) Nanoparticles. Chem. Soc. Rev. 2012, 41, 8009-8020.

(3) Gao, F.; Wang, Y. L.; Goodman, D. W. Reaction Kinetics and Polarization-Modulation Infrared Reflection Absorption Spectroscopy (PM-IRAS) Investigation of CO Oxidation over Supported Pd-Au Alloy Catalysts. J. Phys. Chem. C 2010, 114, 4036-4043.

(4) Xu, J.; White, T.; Li, P.; He, C. H.; Yu, J. G.; Yuan, W. K.; Han, Y. F. Biphasic Pd-Au Alloy Catalyst for Low-Temperature CO Oxidation. J. Am. Chem. Soc. 2010, 132, 10398-10406.

(5) Han, Y. F.; Wang, J. H.; Kumar, D.; Yan, Z.; Goodman, D. W. A Kinetic Study of Vinyl Acetate Synthesis over Pd-Based Catalysts: Kinetics of Vinyl Acetate Synthesis over $\mathrm{Pd}-\mathrm{Au} / \mathrm{SiO}_{2}$ and $\mathrm{Pd} / \mathrm{SiO}_{2}$ Catalysts. J. Catal. 2005, 232, 467-475.

(6) Chen, M. S.; Kumar, D.; Yi, C. W.; Goodman, D. W. The Promotional Effect of Gold in Catalysis by Palladium-Gold. Science 2005, 310, 291-293.

(7) Enache, D. I.; Edwards, J. K.; Landon, P.; Solsona-Espriu, B.; Carley, A. F.; Herzing, A. A.; Watanabe, M.; Kiely, C. J.; Knight, D. W.; 
Hutchings, G. J. Solvent-Free Oxidation of Primary Alcohols to Aldehydes Using Au-Pd/TiO ${ }_{2}$ Catalysts. Science 2006, 311, 362-365.

(8) Ketchie, W. C.; Murayama, M.; Davis, R. J. Selective Oxidation of Glycerol over Carbon-Supported AuPd Catalysts. J. Catal. 2007, 250, 264-273.

(9) Zhang, H. J.; Watanabe, T.; Okumura, M.; Haruta, M.; Toshima, N. Catalytically Highly Active Top Gold Atom on Palladium Nanocluster. Nat. Mater. 2012, 11, 49-52.

(10) Hutchings, G. J. Nanocrystalline Gold and Gold Palladium Alloy Catalysts for Chemical Synthesis. Chem. Commun. 2008, 1148-1164.

(11) Edwards, J. K.; Solsona, B.; Edwin, N. N.; Carley, A. F.; Herzing, A. A.; Kiely, C. J.; Hutchings, G. J. Switching Off Hydrogen Peroxide Hydrogenation in the Direct Synthesis Process. Science 2009, 323, 1037-1041.

(12) Campbell, C. T. Bimetallic Surface Chemistry. Annu. Rev. Phys. Chem. 1990, 41, 775-837.

(13) Somorjai, G. A. Modern Surface Science and Surface Technologies: An Introduction. Chem. Rev. 1996, 96, 1223-1235.

(14) Weaver, J. F.; Carlsson, A. F.; Madix, R. J. The Adsorption and Reaction of Low Molecular Weight Alkanes on Metallic Single Crystal Surfaces. Surf. Sci. Rep. 2003, 50, 107-199.

(15) Gong, J. L. Structure and Surface Chemistry of Gold-Based Model Catalysts. Chem. Rev. 2012, 112, 2987-3054.

(16) Pan, M.; Brush, A. J.; Pozun, Z. D.; Ham, H. C.; Yu, W.-Y.; Henkelman, G.; Hwang, G. S.; Mullins, C. B. Model Studies of Heterogeneous Catalytic Hydrogenation Reactions with Gold. Chem. Soc. Rev. 2013, 42, 5002-5013.

(17) Conrad, H.; Ertl, G.; Kuppers, J.; Latta, E. E. Interaction of NO and $\mathrm{O}_{2}$ with $\mathrm{Pd}(111)$ surfaces. II. Surf. Sci. 1977, 65, 245-260.

(18) Matsushima, T. Dissociation of Oxygen Admolecules on $\mathrm{Rh}(111), \operatorname{Pt}(111)$ and $\mathrm{Pd}(111)$ Surfaces at Low Temperatures. Surf. Sci. 1985, 157, 297-318.

(19) Imbihl, R; Demuth, J. E. Adsorption of Oxygen on A Pd(111) Surface Studied by High Resolution Electron Energy Loss Spectroscopy (EELS). Surf. Sci. 1986, 173, 395-410.

(20) Guo, X. C.; Hoffman, A.; Yates, J. T. Adsorption Kinetics and Isotopic Equilibration of Oxygen Adsorbed on the $\mathrm{Pd}(111)$ Surface. J. Chem. Phys. 1989, 90, 5787-5792.

(21) Kolasinski, K. W.; Cemic, F.; Hasselbrink, E. $\mathrm{O}_{2} / \mathrm{Pd}(111)$ Clarification of the Correspondence between Thermal-Desorption Features and Chemisorption States. Chem. Phys. Lett. 1994, 219, 113117.

(22) Rose, M. K.; Borg, A.; Dunphy, J. C.; Mitsui, T.; Ogletree, D. F.; Salmeron, M. Chemisorption and Dissociation of $\mathrm{O}_{2}$ on $\mathrm{Pd}(111)$ Studied by STM. Surf. Sci. 2003, 547, 162-170.

(23) Nolan, P. D.; Lutz, B. R.; Tanaka, P. L.; Mullins, C. B. Direct Verification of A High-Translational-Energy Molecular Precursor to Oxygen Dissociation on Pd(111). Surf. Sci. 1998, 419, L107-L113.

(24) Min, B. K.; Friend, C. M. Heterogeneous Gold-Based Catalysis for Green Chemistry: Low-Temperature CO Oxidation and Propene Oxidation. Chem. Rev. 2007, 107, 2709-2724.

(25) Li, Z. J.; Gao, F.; Tysoe, W. T. Carbon Monoxide Oxidation over $\mathrm{Au} / \mathrm{Pd}(100)$ Model Alloy Catalysts. J. Phys. Chem. C 2010, 114, 16909-16916.

(26) Gao, F.; Wang, Y. L.; Goodman, D. W. CO Oxidation over $\operatorname{AuPd}(100)$ from Ultrahigh Vacuum to Near-Atmospheric Pressures: The Critical Role of Contiguous Pd Atoms. J. Am. Chem. Soc. 2009, 131, 5734-5735.

(27) Piednoir, A.; Languille, M. A.; Piccolo, L.; Valcarcel, A.; Aires, F.; Bertolini, J. C. $\mathrm{Pd}(111)$ versus $\mathrm{Pd}-\mathrm{Au}(111)$ in Carbon Monoxide Oxidation under Elevated Pressures. Catal. Lett. 2007, 114, 110-114.

(28) Zhang, J.; Jin, H. M.; Sullivan, M. B.; Chiang, F.; Lim, H.; Wu, P. Study of Pd-Au Bimetallic Catalysts for CO Oxidation Reaction by DFT Calculations. Phys. Chem. Chem. Phys. 2009, 11, 1441-1446.

(29) Ham, H. C.; Hwang, G. S.; Han, J.; Nam, S. W.; Lim, T. H. On the Role of Pd Ensembles in Selective $\mathrm{H}_{2} \mathrm{O}_{2}$ Formation on PdAu Alloys. J. Phys. Chem. C 2009, 113, 12943-12945.

(30) Ham, H. C.; Hwang, G. S.; Han, J.; Nam, S. W.; Lim, T. H. Geometric Parameter Effects on Ensemble Contributions to Catalysis:
$\mathrm{H}_{2} \mathrm{O}_{2}$ Formation from $\mathrm{H}_{2}$ and $\mathrm{O}_{2}$ on AuPd Alloys. A First Principles Study. J. Phys. Chem. C 2010, 114, 14922-14928.

(31) Ham, H. C.; Stephens, J. A.; Hwang, G. S.; Han, J.; Nam, S. W.; Lim, T. H. Pd Ensemble Effects on Oxygen Hydrogenation in AuPd Alloys: A Combined Density Functional Theory and Monte Carlo Study. Catal. Today 2011, 165, 138-144.

(32) Ham, H. C.; Stephens, J. A.; Hwang, G. S.; Han, J.; Nam, S. W.; Lim, T. H. Role of Small Pd Ensembles in Boosting CO Oxidation in AuPd Alloys. J. Phys. Chem. Lett. 2012, 3, 566-570.

(33) Garcia-Mota, M.; Lopez, N. The Role of Long-Lived Oxygen Precursors on AuM Alloys $(\mathrm{M}=\mathrm{Ni}, \mathrm{Pd}, \mathrm{Pt})$ in CO Oxidation. Phys. Chem. Chem. Phys. 2011, 13, 5790-5797.

(34) Wang, T. Y.; Li, B. H.; Yang, J. H.; Chen, H.; Chen, L. A. First Principles Study of Oxygen Adsorption and Dissociation on the $\mathrm{Pd} / \mathrm{Au}$ Surface Alloys. Phys. Chem. Chem. Phys. 2011, 13, 7081-7089.

(35) Yuan, D. W.; Liu, Z. R.; Chen, J. H. Catalytic Activity of Pd Ensembles over $\mathrm{Au}(111)$ Surface for CO Oxidation: A First-Principles Study. J. Chem. Phys. 2011, 134, 054704.

(36) Yuan, D. W.; Liu, Z. R.; Xu, S. First-Principles Investigations of $\mathrm{O}_{2}$ Dissociation on Low-Coordinated Pd Ensembles over Stepped $\mathrm{Au}$ Surfaces. Phys. Lett. A 2012, 376, 3432-3438.

(37) Yuan, D. W.; Liu, Z. R. Catalytic Activity of Pd Ensembles Incorporated into Au Nanocluster for $\mathrm{CO}$ oxidation: A First-Principles Study. Phys. Lett. A 2011, 375, 2405-2410.

(38) Kim, H. Y.; Henkelman, G. CO Adsorption-Driven Surface Segregation of Pd on Au/Pd Bimetallic Surfaces: Role of Defects and Effect on CO Oxidation. ACS Catal. 2013, 3, 2541-2546.

(39) Cheng, D. J.; Xu, H. X.; Fortunelli, A. Tuning the Catalytic Activity of Au-Pd Nanoalloys in CO Oxidation via Composition. J. Catal. 2014, 314, 47-55.

(40) Flaherty, D. W.; Hahn, N. T.; Ferrer, D.; Engstrom, T. R.; Tanaka, P. L.; Mullins, C. B. Growth and Characterization of High Surface Area Titanium Carbide. J. Phys. Chem. C 2009, 113, 1274212752.

(41) Flaherty, D. W.; Yu, W.-Y.; Pozun, Z. D.; Henkelman, G.; Mullins, C. B. Mechanism for the Water-Gas Shift Reaction on Monofunctional Platinum and Cause of Catalyst Deactivation. J. Catal. 2011, 282, 278-288.

(42) Yu, W.-Y.; Mullen, G. M.; Mullins, C. B. Hydrogen Adsorption and Absorption with Pd-Au Bimetallic Surfaces. J. Phys. Chem. C 2013, 117, 19535-19543.

(43) Yu, W.-Y.; Mullen, G. M.; Mullins, C. B. Interactions of Hydrogen and Carbon Monoxide on Pd-Au Bimetallic Surfaces. J. Phys. Chem. C 2014, 118, 2129-2137.

(44) Yu, W.-Y.; Mullen, G. M.; Flaherty, D. W.; Mullins, C. B. Selective Hydrogen Production from Formic Acid Decomposition on Pd-Au Bimetallic Surfaces. J. Am. Chem. Soc. 2014, 136, 11070-11078.

(45) Koel, B. E.; Sellidj, A.; Paffett, M. T. Ultrathin Films of Pd on $\mathrm{Au}(111)$ - Evidence for Surface Alloy Formation. Phys. Rev. B 1992, $46,7846-7856$.

(46) King, D. A.; Wells, M. G. Reaction Mechanism in Chemisorption Kinetics - Nitrogen on $\{100\}$ Plane of Tungsten. Proc. R. Soc. London, Ser. A 1974, 339, 245-269.

(47) Wheeler, M. C.; Seets, D. C.; Mullins, C. B. Kinetics and Dynamics of the Initial Dissociative Chemisorption of Oxygen on $\mathrm{Ru}(001)$. J. Chem. Phys. 1996, 105, 1572-1583.

(48) Davis, J. E.; Karseboom, S. G.; Nolan, P. D.; Mullins, C. B. Kinetics and Dynamics of the Initial Adsorption of Nitric Oxide on $\operatorname{Ir}(111)$. J. Chem. Phys. 1996, 105, 8362-8375.

(49) Davis, J. E.; Nolan, P. D.; Karseboom, S. G.; Mullins, C. B. Kinetics and Dynamics of the Dissociative Chemisorption of Oxygen on $\operatorname{Ir}(111)$. J. Chem. Phys. 1997, 107, 943-952.

(50) Kresse, G.; Hafner, J. Ab Initio Molecular Dynamics for Liquid Metals. Phys. Rev. B 1993, 47, 558-561.

(51) Kresse, G.; Hafner, J. Ab Initio Molecular-Dynamics Simulation of the Liquid-Metal-Amorphous-Semiconductor Transition in Germanium. Phys. Rev. B 1994, 49, 14251-14269. 
(52) Kresse, G.; Furthmuller, J. Efficient Iterative Schemes for Ab Initio Total-Energy Calculations Using A Plane-Wave Basis Set. Phys. Rev. B 1996, 54, 11169-11186.

(53) Kresse, G.; Furthmuller, J. Efficiency of Ab-Initio Total Energy Calculations for Metals and Semiconductors Using A Plane-Wave Basis Set. Comput. Mater. Sci. 1996, 6, 15-50.

(54) Blochl, P. E. Projector Augmented-Wave Method. Phys. Rev. B 1994, 50, 17953-17979.

(55) Hohenberg, P.; Kohn, W. Inhomogeneous Electron Gas. Phys. Rev. B 1964, 136, B864-B871.

(56) Kohn, W.; Sham, L. J. Self-Consistent Equations Including Exchange and Correlation Effects. Phys. Rev. 1965, 140, 1133-1138.

(57) Perdew, J. P.; Burke, K.; Ernzerhof, M. Generalized Gradient Approximation Made Simple. Phys. Rev. Lett. 1996, 77, 3865-3868.

(58) Henkelman, G.; Uberuaga, B. P.; Jonsson, H.; Climbing Image, A. Nudged Elastic Band Method for Finding Saddle Points and Minimum Energy Paths. J. Chem. Phys. 2000, 113, 9901-9904.

(59) Henkelman, G.; Jonsson, H. Improved Tangent Estimate in the Nudged Elastic Band Method for Finding Minimum Energy Paths and Saddle Points. J. Chem. Phys. 2000, 113, 9978-9985.

(60) Monkhorst, H. J.; Pack, J. D. Special Points for Brillouin-Zone Integrations. Phys. Rev. B 1976, 13, 5188-5192.

(61) Yi, C. W.; Luo, K.; Wei, T.; Goodman, D. W. The Composition and Structure of Pd-Au Surfaces. J. Phys. Chem. B 2005, 109, 1853518540 .

(62) Wei, T.; Wang, J.; Goodman, D. W. Characterization and Chemical Properties of Pd-Au Alloy Surfaces. J. Phys. Chem. C 2007, $111,8781-8788$.

(63) Li, Z.; Gao, F.; Wang, Y.; Calaza, F.; Burkholder, L.; Tysoe, W. $\mathrm{T}$. Formation and characterization of $\mathrm{Au} / \mathrm{Pd}$ surface alloys on Pd(111). Surf. Sci. 2007, 601, 1898-1908.

(64) Trenary, M. Reflection Absorption Infrared Spectroscopy and the Structure of Molecular Adsorbates on Metal Surfaces. Annu. Rev. Phys. Chem. 2000, 51, 381-403.

(65) Meier, D. C.; Bukhtiyarov, V.; Goodman, D. W. CO Adsorption on $\mathrm{Au}(110)-(1 \times 2)$ : An IRAS Investigation. J. Phys. Chem. B 2003, 107, 12668-12671.

(66) Campbell, C. T.; Arnadottir, L.; Sellers, J. R. V. Kinetic Prefactors of Reactions on Solid Surfaces. Z. Phys. Chem. 2013, 227, $1435-1454$.

(67) Kolasinski, K. W.; Cemic, F.; Demeijere, A.; Hasselbrink, E. Interactions in Co-Adsorbed $\mathrm{CO}+\mathrm{O}_{2} / \mathrm{Pd}(111)$ Layers. Surf. Sci. 1995, $334,19-28$.

(68) Engel, T.; Ertl, G. Surface Residence Times and Reaction Mechanism in Catalytic Oxidation of $\mathrm{CO}$ on $\mathrm{Pd}(111)$. Chem. Phys. Lett. 1978, 54, 95-98.

(69) Conrad, H.; Ertl, G.; Kuppers, J. Interactions between Oxygen and Carbon Monoxide on A Pd(111) Surface. Surf. Sci. 1978, 76, 323342.

(70) Engel, T.; Ertl, G. A Molecular Beam Investigation of Catalytic Oxidation of $\mathrm{CO}$ on $\mathrm{Pd}(111)$. J. Chem. Phys. 1978, 69, 1267-1281.

(71) Libuda, J.; Freund, H. J. Molecular Beam Experiments on Model Catalysts. Surf. Sci. Rep. 2005, 57, 157-298. 